\title{
CONFIGURACIÓN ESPACIO-TEMPORAL DE LA SANTIDAD FEMENINA MEDIEVAL EN LA VIDA DE SANTA MARÍA EGIPCIACA
}

\author{
Carina Zubillaga \\ SECRIT (IIBICRIT-CONICET) - Universidad de Buenos Aires \\ carinazubillaga@hotmail.com
}

\begin{abstract}
RESUMEN: La medida del espacio y del tiempo en la Vida de Santa María Egipciaca, poema castellano del temprano siglo XIII, promueve el desarrollo textual de la leyenda de esta prostituta arrepentida a través de la dinámica inicial del viaje de la pecadora y su posterior estancia penitencial en el desierto durante más de cuarenta años, primando la descripción sobre la narración a medida que la mujer alcanza la santidad. La santidad femenina del desierto se configura mediante la autorización y testimonio eclesiásticos, representados aquí por Gozimás y los monjes de la abadía de San Juan, verdaderos modelos de la posibilidad de vida cristiana comunitaria durante el período.
\end{abstract}

PALABRAS CLAVE: espacio, tiempo, santidad femenina, prostituta arrepentida, siglo XIII, poesía hagiográfica.

\section{SPACE-TIME CONFIGURATION OF THE MEDIEVAL FEMALE HOLINESS IN THE VIDA DE SANTA MARÍA EGIPCIACA}

\begin{abstract}
The shape of space and time in the Vida de Santa María Egipciaca, a $13^{\text {th }}$ century Castilian poem, promotes the textual development of the legend of the repentant prostitute through the dynamics of the initial travel of the sinful and her subsequent penitential stay in the desert for more than forty years, giving priority to the description on the narration when the women reaches the holiness. The female holiness of the desert takes form through ecclesiastical authorization and testimony, represented here by Gozimás and the monks of the Abbey of St. John, real models of the possibility of communitiy Christian life in the period.
\end{abstract}

KEYWORDS: space, time, female holiness, repentant prostitute, $13^{\text {th }}$ century, hagiographical poetry. 
La Vida de Santa María Egipciaca, el poema castellano de mediados del siglo XIII que traduce el poema francés Vie de Sainte Marie l'Égyptienne, se conserva en un manuscrito de fines del siglo XIV que reúne tres textos con más similitudes que diferencias entre sí: el códice K-III-4 de la Biblioteca de San Lorenzo de El Escorial ${ }^{1}$. Entre las semejanzas que es posible plantear entre la vida de la pecadora arrepentida, el Libro de Apolonio - poema que principia el códice- y el Libro de los tres reyes de Oriente -el poema final, además de las numerosas coincidencias temáticas de estas biografías o pseudo-biografías en las cuales el eje central es el conflicto entre la virtud y el vicio, puede apreciarse que la estructura narrativa de cada uno de los poemas está basada en la dinámica del viaje como movimiento de la trama y del desarrollo vital de los personajes. Si hay algo que define a Apolonio, a María de Egipto y a la Sagrada Familia en su conjunto es que son viajeros cuyas trayectorias remiten a la vez a una linealidad espacial recorrida en cierto tiempo y a la configuración simbólica de esos mismos viajes como pruebas cristianas.

Tanto la Vida de Santa María Egipciaca como los otros dos poemas que componen el Ms. Esc. K-III-4 no son concretamente, sin embargo, relatos de viajes, a pesar de que el viaje promueve el avance textual y determina el doble registro narrativo y descriptivo que caracteriza a las historias ${ }^{2}$. En las hagiografías medievales, numerosas vidas de santos y santas se estructuran a partir de la dinámica de un viaje que es a la vez desplazamiento literal y camino figurativo a la santidad; esto ocurre particularmente en el caso de personajes que sólo alcanzan esa santidad después de un arduo proceso de transformación interior que en muchos casos se explicita como trayectoria exterior, como sucede efectivamente con María de Egipto.

La leyenda occidental de María Egipciaca, prototipo de la pecadora arrepentida junto con María Magdalena, se centra en la santidad como un proceso que es narrado a partir del marco biográfico que lo pauta. A diferencia de las versiones orientales previas de la historia de María de Egipto, en las cuales la misma santa refería en primera persona al monje Zózimas toda su vida desde el presente de su casi concluida penitencia, las versiones occidentales que surgen en Europa a partir de fines del siglo XII dan cuenta de esa vida en tercera persona y en estricto orden

1. Para ahondar en la conformación unitaria del manuscrito, ver mi estudio y edición del mismo (Zubillaga 2014).

2. Remito a Zumthor, quien plantea la predominancia alternada de un registro sobre otro en los relatos que involucran viajes, para así conferirle al texto su tono general (1994: 289). 
cronológico, iniciándose con la infancia y juventud de María y culminando con el momento mismo de su muerte ${ }^{3}$.

Todo viajero recorre un espacio en el transcurso del tiempo y esta articulación impulsa las grandes alternancias entre secuencias descriptivas (espacio) y narrativas (tiempo) del relato de ese viaje, que si se equipara a la historia de toda su vida como en el caso de María de Egipto- asume la forma de avances y detenciones que se configuran literariamente en el contrapunto entre lo referido y lo descripto. En la Vida de Santa María Egipciaca esa combinación determina secuencias espacio-temporales en las cuales la descripción se impone textualmente sobre la narración, estableciendo la predominancia de la estabilidad sobre el movimiento, del espacio sobre el tiempo, del desierto como lugar que es imagen de la transformación interior y la sintetiza mediante la autonomía descriptiva que adquiere la penitencia en la segunda y concluyente parte del poema. Así como en los libros específicamente de viajes ese carácter nuclear de la descripción se concentra en la información y el detalle de las tierras recorridas, en la hagiografía eremítica explota el espacio del desierto en toda su dimensión paradójica como lugar donde parece no existir nada más allá de la soledad y la carencia, pero que justamente por ello posibilita que pueda concurrir y suceder todo.

El movimiento que caracteriza la primera parte de la Vida de Santa María Egipciaca es la cifra de la narración del carácter siempre creciente del pecado, que avanza y aumenta a medida que la protagonista también crece. La bondad que se abandona y el pecado que se adquiere y se incrementa indican el paso de la niñez a la juventud de María ("Mientre que fue en mancebía, / dexó bondat e preso folía", 85-864), quien decide abandonar su hogar natal para dar rienda suelta a su lujuria sin controles familiares ("por más fer su voluntat, / irse querié de la çibdat", 133-134).

El viaje de la pecadora a Alejandría implica concretamente el avance del pecado en su vida, aunque ese aumento asume la forma singular de la reducción implícita en la marginalidad; la ciudad en sí misma no se describe y se reduce a ser apenas el lugar de la prostitución como el espacio marginal donde se desarrolla la lujuria de María:

3. Ver especialmente Robertson para profundizar en las distinciones entre las versiones orientales y occidentales de la leyenda de María Egipciaca (1980: 305-327).

4. Las citas corresponden a mi propia transcripción del poema presente en la edición conjunta del Ms. Esc. K-III-4 (Zubillaga 2014); indico a continuación de cada una el número de versos correspondientes. 
En Alexandria fue María, aquí demanda alverguería; allá va prender ostal con las malas en la cal. $(147-150)$

La relación de la sociedad con el espacio de la ciudad está claramente determinada en esta idea de marginalidad, que privilegia la actividad de la prostitución que se narra en una sucesión indeterminada de días y noches por sobre cualquier descripción: "En bever e en comer e folía / cuidava noche e día" (165-166).

La oposición margen-centro que ubica a la pecadora en la periferia propia de las prostitutas y otros no integrados en la sociedad distingue el espacio de la marginalidad como el del movimiento continuo; un movimiento peligroso que se contrapone a la estabilidad social, pues el pecado hace que de un momento a otro se pase del placer y el divertimento al extremo opuesto de la pelea y la muerte: "Tantas hí van de conpañas / que los juegos tornan a sañas" (175-176). El avance continuo del pecado y de la muerte que ese pecado conlleva está representado por la imagen de la sangre derramada en esa misma calle que alberga a María ("dávanse grandes espadadas. / La sangre que dellos salía / por medio de la cal corría”, 178-180) y se distingue en su movimiento creciente de la inmovilidad interior de la pecadora, que en nada se conduele ni reacciona frente a los males que ella misma genera ("La cativa, quando lo vedié, / nula piedat no le prendié", 181-182).

El posterior viaje por mar de María incentiva aún más la movilidad del pecado, al punto de volverse tentación hasta para los peregrinos que viajan a Jerusalén para celebrar el día de Ascensión de la Virgen. La narración de la lujuria irrefrenable e ilimitada de María en el barco asume el matiz progresivo que se expresa en la sucesión de los pasos requieridos para que se concrete el acto sexual: "Primerament los va tentando, / después los va abraçando; / e luego se va con ellos echando" (373-375). La trayectoria de navegación adquiere de ese modo la forma del movimiento del pecado de María, que se iguala a las olas del mar que nunca se detienen: "toda la noche andan a las estrellas; / más de dormir non á ý nada, / que María es aparellada" (366-368). El carácter inmotivado del viaje mismo ("irme querría daqueste logar, / non he talante daquí estar", 301-302) da cuenta de ese poder creciente y arrollador del pecado que actúa más allá incluso de la voluntad de la prostituta y la moviliza en la travesía marítima que será el espacio-tiempo culminante de su pecado pero, al mismo tiempo, el inicio de la estabilidad posterior determinada por la prohibición de entrar al templo a la vez como límite y como primera frontera. 
María no puede ingresar al templo el día de la Ascensión, como sí lo hacen los demás peregrinos, porque fuerzas sobrenaturales le impiden la entrada. Son esos caballeros celestiales ("cada uno tenié su espada, / menazávanla a la entrada", 448-449) los que detienen tanto el avance concreto de María como el movimiento hasta entonces creciente del pecado representado por su lujuria incontrolable. El primer límite infranqueable que aparece entonces en la Vida de Santa María Egipciaca es el que separa el espacio profano del espacio sagrado de la iglesia; una frontera controlada por fuerzas divinas que distingue la vida de pecado de la gracia salvífica cristiana de manera antes simbólica que material, aunque se perciba materialmente.

La oración que la pecadora le dirige entonces a la Virgen María, arrepintiéndose de su vida anterior y rogándole su intercesión y auxilio para obtener el perdón de sus pecados, le permite a María Egipciaca asumir en su propia persona ese límite antes impuesto, lo que se aprecia en la disposición de su cuerpo arrodillado, controlado e incluso casi inmóvil frente a la imagen de la Virgen: "los inojos ant'ella fincó, / tan con vergüença la cató; / atán piadosament la reclamó" (480-482).

El siguiente trayecto de María Egipciaca, el que inaugurará su penitencia, se anuncia como mensaje profético antes de concretarse y también refuerza el carácter simbólico antes que material del espacio-tiempo penitencial, ya que esa estancia en el desierto es ordenada por una voz celestial y regulada en todo el detalle de su itinerario, dejando en claro que tanto los límites como los avances serán de ahí en más un designio divino a cumplir para alcanzar la salvación:

Una boz oyó veramente que le dixo paladinamiente:

"Ve a la ribera de sant Jordán, al monesterio de Sant Johán. Una melezina prenderás, de todos tus pecados sanarás; Corpus Christi te darán e fuente Jordán te passarán. Depués entrarás en un yermo e morarás hí un grant tienpo.

En el yermo estarás, fasta que bivas hí te despendrás”. (632-643) 
Ya en esta profecía puede advertirse el cambio de orientación textual que se producirá, ya que a modo de resumen de lo que resta del poema la voz celestial cual sustituta de la voz narrativa- anuncia que María no viajará más, sino que ingresará en el desierto en el que vivirá hasta el momento mismo de su muerte, deteniéndose de ese modo el movimiento como imagen tanto del pecado como de la acción narrativa y el paso del tiempo en el poema para priorizarse la descripción del desierto como espacio de la transformación interior base de la penitencia.

El río Jordán es la nueva frontera, en este caso acuática, que vehiculiza la conversión obrada a partir del límite sobrenatural del templo por medio de la penitencia como expresión del cambio de una vida de pecado a otra que es anhelo de santidad. La simbología del rito de pasaje queda clara en la multiplicidad de sentidos que el Jordán convoca, siendo tanto el agua que calma la sed de la protagonista ("bevió del agua que era santa; / quando la bevió, toda fue farta", 660661) como la imagen bautismal que principia su proceso de purificación y transformación ("Lava la tiesta en la onda, / de sus pecados se sintió monda", 662-663). El carácter también sobrenatural del río Jordán como frontera es evidente en su relación con la historia sagrada, ya que sus aguas refieren al bautismo de Jesús por Juan el Bautista ${ }^{5}$. Esta frontera, sin embargo, no funciona como un límite, como sí lo hacía la barrera de los enviados celestiales en el templo; antes bien, es un espacio concurrente, capaz de unir y no de separar, de hacer coincidir y no de relegar, lo que se comprueba cuando María Egipciaca vuelve a atravesar sus aguas para recibir la comunión de parte de Gozimás, caminando sobre ellas en una referencia crística innegable que confirma el proceso de su santidad:

\footnotetext{
"Dios, dixo, en que yo creyo, déxame veyer lo que deseyo". A la otra parte la vio estar; luego comiença de fablar: "Dueña, dixo Gozimás, cara mi madre, ¿qué farás?”. Quando María lo oyó fablar, de nula res non querié dubdar. Sobr'el agua vinié María, como si viniese por una vía. A la ribera vino en ascucha; don Gozimás luego la saluda. (1242-1253)
}

5. Como señala Gracia, "El eco del bautismo de Jesús por parte de san Juan Bautista es evidente a orillas del Jordán, donde la iglesia y el monasterio de San Juan parecen venerar su recuerdo" (2001: 206). 
El desierto es el espacio distintivo de la penitencia de María en toda la segunda parte del poema, siendo también su figura además de su representación; la penitencia ya no se relata según la dinámica vital y textual del viaje, como sí se hacía con la narración creciente del pecado y su poder sobre los hombres previamente en el texto, sino que es apenas un vagabundeo, un ir y venir que no conduce muy lejos y que en cambio necesita describirse en su carácter inconmensurable.

Frente al movimiento del pecado anterior, en la instalación penitencial todo se detiene; incluso el tiempo parece detenerse, ya que se mide en la duración efímera de la vestimenta de María como resabio del pasado que se vuelve presente en la imagen sí más sustancialmente durativa de la desnudez del cuerpo de la penitente:

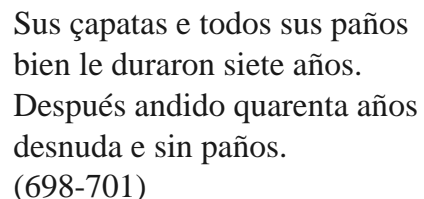

Esos cuarenta y siete años que permanece María en el desierto se comprimen en su retrato como anacoreta, a través de una descripción retórica que se opone al retrato de su juventud presente en el inicio del poema. La penitencia se traduce en un deterioro corporal que a las características propias de la vejez suma un aspecto salvaje que convierte a la santa en un ser del desierto, despojándola de sus atributos femeninos: "en sus pechos non avía tetas, / como yo cuido eran secas" (738-739), animalizándola: "tornó María a las yerbas del campo; / como otra bestia las mascava" (769-770) y equiparando por lo tanto su figura a la del hombre salvaje.

El prototipo del hombre salvaje ${ }^{6}$, presente en la cultura medieval europea desde sus orígenes cristianos pero en particular a partir del siglo XII, se asocia con el del anacoreta a través del desierto como espacio de la ascesis más solitaria. Las condiciones climáticas rigurosas, los animales salvajes, la carencia total e incluso las tentaciones demoníacas, entre tantos otros peligros del desierto, definen la medida de una ascesis salvaje en la cual la superación de la naturaleza humana se expresa de manera singular bajo el más bestial de los aspectos.

El desarrollo medieval del paradigma del ser salvaje santo pone de manifiesto la complejidad del espacio del desierto para el Cristianismo: es a la vez el lugar de

6. Acosta (1996: 127) describe al hombre salvaje como aquel que vive y se comporta como bestia, en un medio natural, fuera de la sociedad y de sus leyes. 
la tentación diabólica y de la posibilidad del encuentro íntimo con Dios, el sitio de la soledad absoluta y del reconocimiento del género humano, la oportunidad única de que la prueba extrema y la conciencia de los propios límites devengan santidad. Claramente, en la Vida de Santa María Egipciaca el desierto no es en verdad una representación exacta del espacio árido que alberga la penitencia de la antes prostituta, o no solo, sino que connota el espacio estereotipado de la historia sagrada; un espacio literario, en el cual convergen la geografía y la retórica.

En cuanto a la articulación entre espacio y tiempo, este valor simbólico del desierto ancla el relato en una larga estancia de la que se da cuenta mediante la descripción de ese espacio como elemento estructurante. Al contrario de lo que ocurre en los libros de viajes, que se definen básicamente a partir del itinerario ${ }^{7}$, la estadía en el desierto diluye el peso del itinerario, que pierde su carácter de representación geográfica concreta y recorrido cronológico lineal y se desdibuja a medida que avanza la historia de María, pasándose de los días a las semanas y de los meses a los años con una significativa rapidez en un espacio que parece nunca cambiar.

El desierto es en el poema un espacio efectivamente casi atemporal, y asimismo asexuado y asocial, que paradójicamente sin embargo requiere la presencia de un testigo de la santidad de la penitente para que la misma pueda volverse testimonio cristiano; un hombre en este caso que, aunque monje en su penitencia cuaresmal, altera aparentemente en principio la estabilidad, la pérdida de toda feminidad y la soledad de la anacoreta.

Después de la inmovilidad que caracteriza la estancia de María en el desierto durante cuarenta y siete años, el movimiento parece surgir nuevamente en el encuentro entre la mujer y el monje Gozimás; ese movimiento, sin embargo, se revela como un mero atisbo de movilidad, un juego de avance y retroceso que es otra de las formas del vagabundeo penitencial de María Egipciaca.

Apenas Gozimás descubre a la penitente, duda primero en acercarse temiendo una posible tentación diabólica ("El santo homne bien fue enseñado, / contra la sombra va privado", 940-941) y comienza luego a perseguirla después de encomendarse a la protección divina ("Quando el santo omne vio la figura, / allá va a

7. Pérez Priego plantea en este sentido que "[...] en el libro de viajes la narración se articula básicamente sobre el trazado y recorrido de un itinerario, el cual constituye la urdimbre o armazón del relato, de modo semejante, por ejemplo, a la sucesión de reinados o el sistema de anales en el género cronístico" (1984: 220). 
grant pressura", 960-961). María huye del monje ("Quando María lo vio venir, / luego començó de foír", 962-963) y se inicia entonces un seguimiento que promueve el encuentro posterior:

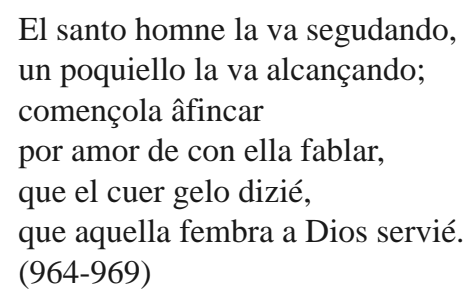

Esa persecución pronto revela su carácter netamente verbal, porque Gozimás declara que lo que en verdad quiere es hablar con la ermitaña ("Por la montaña la va segudando, / apriessa le va fablando: / 'Dueña, diz, fabla comigo'”, 970-972). Al oír el nombre de Dios en la invocación del monje, María se detiene y se entabla entre ambos una conversación agonal en la que cada uno demanda primero la bendición del otro por considerarlo más santo.

Claramente en esa confrontación verbal no hay una perspectiva dual de la ocurrencia de los hechos ni una tensión verdadera; es un mero juego dialógico que suplanta en el poema hispánico cualquier atisbo de galanteo cortés sí apreciable en el poema francés previo ${ }^{8}$. Sin embargo, en un nivel más profundo el mismo contenido de lo que uno y otro plantean revela una oposición entre la vida eremítica y el monacato que anticipa y define tanto los espacios asignados como las propuestas textuales sobre la forma preferible de entrega y vida cristiana.

Para destacar los valores de su contendiente, María explicita los motivos por los que debe recibir primero la bendición del monje como representante de la Iglesia:

Tú eres clérigo misacantano

e pones tus manos en l'altar,

e por el tu santiguar

grandes miraglos faze Dios mostrar.

El pan deviene la su carne,

8. Como especifica Robertson con respecto a la Vie de Sainte Marie l'Égyptienne, "Instinctively we understand Zosimas' and Mary's respective journeyings as phases in a quest. The poet thus evokes the conventions of courtly literature, to entertain, edify, and perhaps ultimately convert his aristocratic lay audience" (1987: 75). 
el vino torna en la su sangre;

bien conosçe Dios tu sacrifiçio, toda tu vida ya la priso.

Non ha en tú nunqua luxuria, nin cobdiçia nin pecunia.

Bien será cosa segurada que de tu mano será santiguada.

(1041-1052)

El monje responde aduciendo las claras señales de santidad que ve en María como resultado de su penitencia, entre las que se destaca la levitación de la mujer como el milagro que corona su primer encuentro: "De tierra fue allí alçada, / que bien hovo una pasada" (1109-1110). La oración de la penitente se dirime como el recurso esencial para mantener la estabilidad de la Iglesia como institución, a pesar de la paz social generalizada supuestamente distintiva del presente, lo que subraya entonces la complementariedad entre su funcionamiento institucional -del que son responsables esencialmente los eclesiásticos- y la gracia de santidad que la sustenta -representada por la penitencia y entrega eremíticas: "Mas santa eglesia es bien con razón / que la metas en tu oraçión” (1101-1102).

El papel complementario que define al clérigo y a la anacoreta a partir de su encuentro no oculta sin embargo la tensión irresuelta de la figura de la pecadora arrepentida como modelo a seguir, que para serlo debe tanto despojarse de los atributos femeninos que en principio la condujeron al arrepentimiento y penitencia por los pecados que su sexualidad extrema provocó ${ }^{9}$ como autenticar eclesiásticamente su santidad y su vínculo íntimo con Dios a través de los sacramentos de la confesión y la comunión, además de sumar a la soledad atemporal distintiva del espacio del desierto la mirada anclada históricamente del monje para que su vida se vuelva un testimonio.

No es casual, en este sentido, por el lugar que ocupará textualmente y por la resignificación de ese espacio, la extensa y favorecedora descripción de la vida de los monjes de la abadía de San Juan; su humildad, su dedicación y su constante servicio a Dios dan cuenta de una comunidad ideal en la que no existe el pecado ("Entr'ellos non avié copdiçia, / ni enbidia nin avariçia", 824-825) y donde la santidad es innegable ("Atanto eran de santa vida / que ay omne que vos lo diga", 830-831).

9. Como señala acertadamente Weiss, "She becomes exemplary once the female body has been purged of the symbolically feminine traits which made it the model of supreme asceticism in the first place" (2006: 92). 
Frente al espacio de la ciudad, en el que la lujuria inicial de María crece cada vez más a pesar de ocupar un espacio marginal, no es el desierto solitario y ascético el que se le opone directamente, como parte de la crítica especializada en el poema ha planteado ${ }^{10}$. María Egipciaca nunca deja de estar al margen de la sociedad, ya sea como prostituta, ya sea como eremita, ni se desprende del aspecto salvaje que una y otra vez la caracteriza; su descontrol lujurioso adquiere la contracara de su desmesura ascética como penitente en el desierto, y tanto su sexualidad desenfrenada como la carencia total posterior de la misma no son la propuesta de vida cristiana postulada como ejemplar por el poema.

A pesar de ser prolongado, el espacio de la penitencia desértica nunca se propone como posibilidad permanente. Los monjes de la abadía de San Juan sólo pasan allí en soledad el momento específico de la Cuaresma, mientras el resto del año lo que se propicia es la vida compartida como representación de la Iglesia en tanto comunidad:

\author{
Quando cumplen su quarentena, \\ antes del jueves de la çena, \\ el domingo de los ramos \\ al monesterio son tornados. \\ $\mathrm{Al}$ santo abat mucho le plazié \\ quando a todos los veyé. \\ Alegre es el pastor con sus corderos \\ quando le vinién enteros. \\ En el monesterio los faze entrar \\ e las puertas faze çerrar.
} (886-895)

El destino final de María Egipciaca también resalta ese carácter transitorio de la penitencia ascética, ya que cuando muere su alma es conducida al cielo como último viaje y a la vez morada permanente. La culminación del poema destaca la idea de la vida como el verdadero viaje, una peregrinatio que sólo se cumple en la comunidad celestial como culminación de la travesía; el Paraíso real cuyo sustituto en la tierra no es el ascetismo desértico que anula hasta la medida

10. Para Cárdenas, por ejemplo, "[...] the world of the city contrasts with the world of the desert, the 'Other World' where María experiences a spiritual transformation of consciousness [...]" (1995: 417). Por su parte, Grieve afirma que " [...] the legend aims to replace the city with a new Paradise on earth and that Mary and the monk Gozimás function as a new or restored Eve and Adam, whose relationship resembles the chaste unions in the Garden of Eden imagined by Agustine [...]" (2000: 133). 
del tiempo ni el carácter asexuado de la relación entre la penitente y su confidente, sino la relación comunitaria desarrollada espacial y temporalmente según la liturgia de la Cuaresma que promueve y divulga todo ejemplo cristiano de santidad. Al final del poema, los mismos monjes resultan los primeros receptores del ejemplo de vida de María Egipciaca ("Mucho emendaron de su vida / por enxemplo desta María", 1438-1439) y son el modelo, por lo tanto, para la ejemplaridad de todos los cristianos facilitada por su testimonio ("E nós mismos nos emendemos, / que mucho mester lo avemos", 1440-1441).

El eremitismo goza de un nuevo impulso en los siglos XII y XIII, como señala Delgado (2003: 50-51), pero basado en el modelo de la vida apostólica que obligaba ahora al eremita a no permanecer eternamente en el desierto, sino a regresar siempre a la vida monástica o episcopal. A pesar de que frente a la primitiva versión oriental de la leyenda María Egipciaca presenta en estos textos occidentales un protagonismo mayor, su imagen no es la esperable como modelo para un público cuya espiritualidad está basada en el ejemplo apostólico; la vida comunitaria de Gozimás, matizada por su estancia cuaresmal en el desierto, continúa siendo en este sentido -aunque por motivos diferentes- todavía la propuesta verdaderamente significativa para el receptor ahora más amplio del poema, que ha incorporado a los laicos como partícipes igualmente importantes de la Iglesia, base fundamental de la divulgación de leyendas hagiográficas como esta de la prostituta santa.

La verdadera oposición espacio-temporal desarrollada en la Vida de Santa María Egipciaca no se da entre la ciudad y el desierto como paraíso terreno alternativo, sino entre lo salvaje y lo civilizado que adquieren diferentes configuraciones y locaciones a través de la idea rectora de margen y centro. La relación más reveladora de la sociedad con el espacio es esta oposición entre lo marginal y lo céntrico, entre el margen que refiere a la soledad (ya sea la de una prostituta en la ciudad rodeada de clientes pero sin relaciones que le importen de veras o la de una eremita cumpliendo su penitencia en medio del desierto) y el centro que representa la vida comunitaria cristiana orientada por el tiempo litúrgico. Como resume Le Goff, acerca del Occidente medieval, "el dualismo fundamental de cultura y naturaleza se expresa más a través de la oposición entre lo que es construido, cultivado y habitado y lo que es propiamente salvaje, universo de los hombres en grupos y universo de la soledad" (1994: 38).

\section{Bibliografía}

ACOSTA, V. (1996). La humanidad prodigiosa. El imaginario antropológico medieval. Venezuela: Monte Ávila Editores. 
CÁRDENAS, A. J. (1995). "The Desert Experience as Other World in the Poem Vida de Santa María Egipciaca”. Romance languages Annual 7: 413-418.

DELGADO, E. E. (2003). "Penitencia y Eucaristía en la conformación de la vertiente occidental de la leyenda de Santa María Egipcíaca: un paradigma de negociación cultural en la Baja Edad Media". Revista de Poética Medieval 10: 25-55.

GRACIA, P. (2001). "Simbología de las aguas en la Vida de Santa María Egipciaca" en Literatura y cristiandad. Homenaje al profesor Jesús Montoya Martínez. (Eds. Manuel José Alonso García, María Luisa Dañobeitia Fernández y Antonio Rafael Rubio Flores). Granada: Universidad de Granada.

GRIEVE, P. E. (2000). "Paradise Regained in Vida de Santa María Egipcíaca: Harlots, the Fall of Nations and Hagiographic Currency" en Translatio Studii: Essays by his Students in Honor of Karl D. Uitti for his Sixty-Fifth Birthday. (Eds. Renate Blumenfeld-Kosinski, Kevin Brownlee, Mary B. Speer \& Lori J. Walters). Amsterdam: Rodopi.

LE GOFF, J. (1994). Lo maravilloso y lo cotidiano en el Occidente medieval. Barcelona: Gedisa.

PÉREZ PRIEGO, M. Á. (1984). "Estudio literario de los libros de viajes medievales". Revista de Filología 1: 217-239.

ROBERTSON, D. (1980). "Poem and Spirit. The Twelfth-Century French Life of saint Mary the Egyptian". Medioevo Romanzo 7 (3): 305-327.

ROBERTSON, D. (1987). "Twelfth-Century Literary Experience: The Life of St. Mary the Egyptian". Pacific Coast Philology 22: 71-77.

WEISS, J. (2006). The "Mester de Clerecía": Intellectuals and Ideologies in Thirteenth-Century Castile. Woodbridge: Tamesis.

ZUBILLAGA, C. (2014). Poesía narrativa clerical en su contexto manuscrito. Estudio y edición del Ms. Esc. K-III-4 ("Libro de Apolonio", "Vida de Santa María Egipciaca", "Libro de los tres reyes de Oriente"). Buenos Aires: SECRIT.

ZUMTHOR, P. (1994). La medida del mundo. Representación del espacio en la Edad Media. Madrid: Cátedra. 